[Article]

\title{
飞秒激光烧蚀含能材料的分子动力学模拟
}

\author{
杨 镇 ${ }^{1}$ 刘 海 $^{2}$ 何远航 ${ }^{1, *}$ \\ ('北京理工大学, 爆炸科学与技术国家重点实验室, 北京 100081; \\ 2 中国空气动力研究与发展中心, 超高速空气动力研究所, 四川绵阳 621000)
}

\begin{abstract}
摘要: 为了得到飞秒激光侵蚀(FLA)1,3 二硝基甲苯(简称 DNB, 分子式: $\mathrm{C}_{6} \mathrm{H}_{4} \mathrm{~N}_{2} \mathrm{O}_{4}$ ), 六硝基六氮杂异伍兹烷 (简称 CL20, 分子式: $\mathrm{C}_{6} \mathrm{H}_{6} \mathrm{~N}_{12} \mathrm{O}_{12}$ ) 和 CL20/DNB共晶系统的物理和化学响应过程, 本文采用 ReaxFF/lg 反应 力场对其过程进行模拟。计算结果表明, CL20/DNB 系统的温度和压力在飞秒激光加载过程中出现阶跃, 激 光加载过程后系统有一个冷却过程, 然后系统的温度和压力逐渐升高达到最大值并维持平衡。研究发现, 在 此过程中 CL20 和 CL20/DNB 系统触发反应均为 CL20 分子中的 N-NO 断裂。CL20 系统的分解速率大于 CL20/DNB共晶系统, 这可能是因为共晶系统在反应初期具有大量的 DNB 分子以及分解产物中含有比较稳 定的苯环减少了CL20 及其产物之间的有效碰撞。
\end{abstract}

关键词: 飞秒激光; CL20/DNB共晶; ReaxFF/lg; 反应机理; 分子动力学

中图分类号: 0643; 0642

\section{Molecular Dynamics Simulations of Femtosecond Laser Ablation of Energetic Materials}

\author{
YANG Zhen ${ }^{1} \quad$ LIU Hai ${ }^{2}$ HE Yuan-Hang ${ }^{1, *}$ \\ ('State Key Laboratory of Explosion Science and Technology, Beijing Institute of Technology, Beijing 100081, P. R. China; \\ ${ }^{2}$ Hypervelocity Aerodynamics Institute, China Aerodynamics Research and Development Center, \\ Mianyang 621000, Sichuan Province, P. R. China)
}

\begin{abstract}
To understand the physical and chemical responses of energetic materials, such as 1,3dinitrobenzene (DNB, $\mathrm{C}_{6} \mathrm{H}_{4} \mathrm{~N}_{2} \mathrm{O}_{4}$ ), hexanitrohexaazaisowurtzitane (CL20, $\mathrm{C}_{6} \mathrm{H}_{6} \mathrm{~N}_{12} \mathrm{O}_{12}$ ), and CL20/DNB co-crystal, to femtosecond laser ablation (FLA), their molecular reaction dynamics have been investigated using the ReaxFF/ $\lg$ force field. The computational results indicate that the temperature and pressure of the CL20/DNB system jump during FLA. In particular, the temperature and pressure gradually reach their maxima following an initial cooling process. $\mathrm{N}-\mathrm{NO}_{2}$ bond breaking of the $\mathrm{CL} 20$ molecule triggers the reactions for both the CL20 and CL20/ DNB systems. However, the CL20 system prevails the CL20/DNB co-crystal in the decomposition rate simply because coexistence of DNB molecules in the mixture and generated decomposition products containing benzene rings greatly reduce the effective collision probability between CL20 and the products.
\end{abstract}

Key Words: Femtosecond laser; CL20/DNB co-crystal; ReaxFF/lg; Reaction mechanism; Molecular dynamics

\section{Introduction}

Femtosecond laser pulse $\mathrm{e}^{1,2}$ is characterized by its short duration and ultra-high peak power. By passing through focusing lens, the laser pulse can invoke nonlinear effects upon interaction with other materials and thereby achieve the capability of ultra-fine processing. FLA has registered pivotal applications in many works including micromachining ${ }^{4-6}$, laser propulsion ${ }^{7}$, and machining energetic materials ${ }^{8}$, to name just a few.

Received: April 19, 2016; Revised: April 28, 2016; Published on Web: April 29, 2016.

${ }^{*}$ Corresponding author. Email: heyuanhang@bit.edu.cn; Tel: +86-10-68918878

(c) Editorial office of Acta Physico-Chimica Sinica 
Femtosecond laser pulse causes no heat transfer and a lowimpact pressure in fine-machining energetic materials, which not only helps dismantle explosives but satisfies sophisticated production of small arms in the arsenal as well ${ }^{8}$.

Up to date there are only a few reports on the employment of the femtosecond laser pulse in machining energetic materials, showing its feasibility ${ }^{9,10}$ and non-involvements of heat transfer and chemical reactions ${ }^{11,12}$ during the processes. By using ANSYS (large finite element analysis software), Chen and co-workers ${ }^{14}$ have further established heat transfer models for the femtosecond laser in cutting propellant ${ }^{13}$ and ablating $\mathrm{Mg}$ /polytetrafluoroethylene. According to detailed calculations of the internal temperature distributions and heat releases, these authors have reached the conclusions that the surface temperatures rise up to over 2500 and $3000 \mathrm{~K}$ for the above-mentioned processes, respectively.

To apply the femtosecond laser machining technology in energetic materials in a safe manner, it is vital to understand the fundamental response processes of the energetic materials involved in their femtosecond laser machining. Due to the ultrashort time scale of the femtosecond laser process, practical experiments encounter tremendous challenges in the attempt to unveil every subtle detail, which becomes actually impossible at the present stage of technology development. This is actually where the theory can fit in. For example, the ReaxFF reactive force field can uncover the physical and chemical response processes of the energetic materials by simultaneous simulations of millions of condensed phase atoms, which is of great complement to the experiment.

ReaxFF reactive force field has been widely applied to study the energetic materials. Numerous simulations ${ }^{15-23}$ have been carried out to investigate the reaction processes of energetic materials under extreme conditions via the ReaxFF reactive force field at the atomic/molecular levels and with a temporal resolution of femtosecond for the initial reaction processes and mechanisms, providing subtle information that can be neither achieved by realistic experiments nor solved with analytical quantum mechanics. However, no studies have been conducted on the FLA of energetic materials by using the ReaxFF reactive force field.

This paper aims at simulating FLA of the hexanitrohexaazaisowurtzitane/1,3-dinitrobenzene (CL20/DNB) co-crystal with the $\mathrm{ReaxFF} / \mathrm{lg}$ reactive force field from LAMMPS Molecular Simulator $^{24}$ program package, exploring the response processes at the atomic scale, and providing the theoretical guidance for the machining safety of energetic materials for practical applications.

\section{Model-building for the simulations}

The unit cell parameters of the crystal structures were adapted from the experimental results of the $1: 1$ molar ratio CL20/DNB co-crystal ${ }^{25}$, pure CL20 ${ }^{25}$, and $\mathrm{DNB}^{26}$ crystals. The supercells used in the simulations are: $(2 \times 2 \times 1)$ for the CL20/DNB co-crystal with 32 CL20 and 32 DNB molecules, $(2 \times 2 \times 2)$ for the CL20 crystal with 32 CL2 0 molecules and $(2 \times 2 \times 1)$ for the DNB crystal with 32 DNB molecules, as shown in Fig.1. In Fig.1, the
$\mathrm{C}, \mathrm{H}, \mathrm{O}, \mathrm{N}$ are represented by grey, white, red, and blue balls, respectively.

Based on uniform velocity distribution, the initial speed of all atoms at $300 \mathrm{~K}$ and optimized atom locations to minimize the potential energy are determined. The whole system was relaxed for $1 \mathrm{ps}$ by using the isothermal-isobaric (commonly called NPT) system to set the pressure and temperature to be $0 \mathrm{~Pa}$ and $300 \mathrm{~K}$, respectively. The yielded unit cell parameters of all three crystals are summarized in Table 1 where the experimental results are also listed for comparisons. Then the systems were thermally elevated up to $4000 \mathrm{~K}$ within $24 \mathrm{fs}$ by using the micro-canonical ensemble (commonly called NVE) method, and elapsed for 40 ps. Time step was set to be $0.02 \mathrm{fs}$, and the bond cutoff, 0.3 . The bond value determines whether or not a new bond forms between atoms. Whenever a bond order of larger than 0.3 establishes, it's taken that new molecules are formed.

\section{Results and discussion}

\subsection{Temperature and pressure evolutions}

Fig. 2 shows the temperature evolutions of different systems during and after their FLA process. When the energetic materials are heated by femtosecond laser to around $4000 \mathrm{~K}$, the system undergoes a rapid cooling process which lasts about $0.2 \mathrm{ps}$, and the temperature decreases to about $2800 \mathrm{~K}$ and dwells for about 0.3 ps, which is caused by endothermic reaction during the initial stage of the reaction. Subsequently, the temperatures for the CL20 and CL20/DNB systems gradually rose up to 5500 and $5000 \mathrm{~K}$, respectively. During this process, both CL20 and CL20/DNB systems release a large amount of heat due to instant decomposition and then reach chemical equilibrium. In addition, while the temperature of the system increases, the CL20 system heats up much faster than the CL20/DNB co-crystal system. However, the temperature of the DNB system dwells at $2800 \mathrm{~K}$ for a period of time up to $20 \mathrm{ps}$ before it increases. During the cooling process $(0-0.5 \mathrm{ps})$, all three systems follow a similar temperature evolution pattern before their trigger reactions come into play.

Fig. 3 shows the pressure evolutions of the three systems during and after their FLA process. During the FLA process, pressure jumps to $8 \mathrm{GPa}$ for the DNB system and reaches $10 \mathrm{GPa}$ for both CL20 and CL20/DNB co-crystal systems. As a matter of fact, the CL20 and CL20/DNB co-crystal systems gradually increase in pressure. It's noticed that the pressure of the CL20 system increases at a greater rate than that of the CL20/DNB co-crystal system. Moreover, the DNB system pressure shows a remarkable declining trend, and eventually fluctuates at $5 \mathrm{GPa}$. The ultimate pressure of the system is equal to about half of Chapman-Jouguet (CJ) detonation pressure, which is consistent with the result calculated using transient detonation theory.

On the whole, in CL20 and CL20/DNB systems, endothermic reaction starts first and leads to the remarkable decrease of the temperature and pressure, and then comes a short period of equilibrium. During this initial reaction process, $\mathrm{N}-\mathrm{NO}_{2}$ of CL20 molecule breaks and the number of $\mathrm{NO}_{2}$ increases sharply. Sub- 


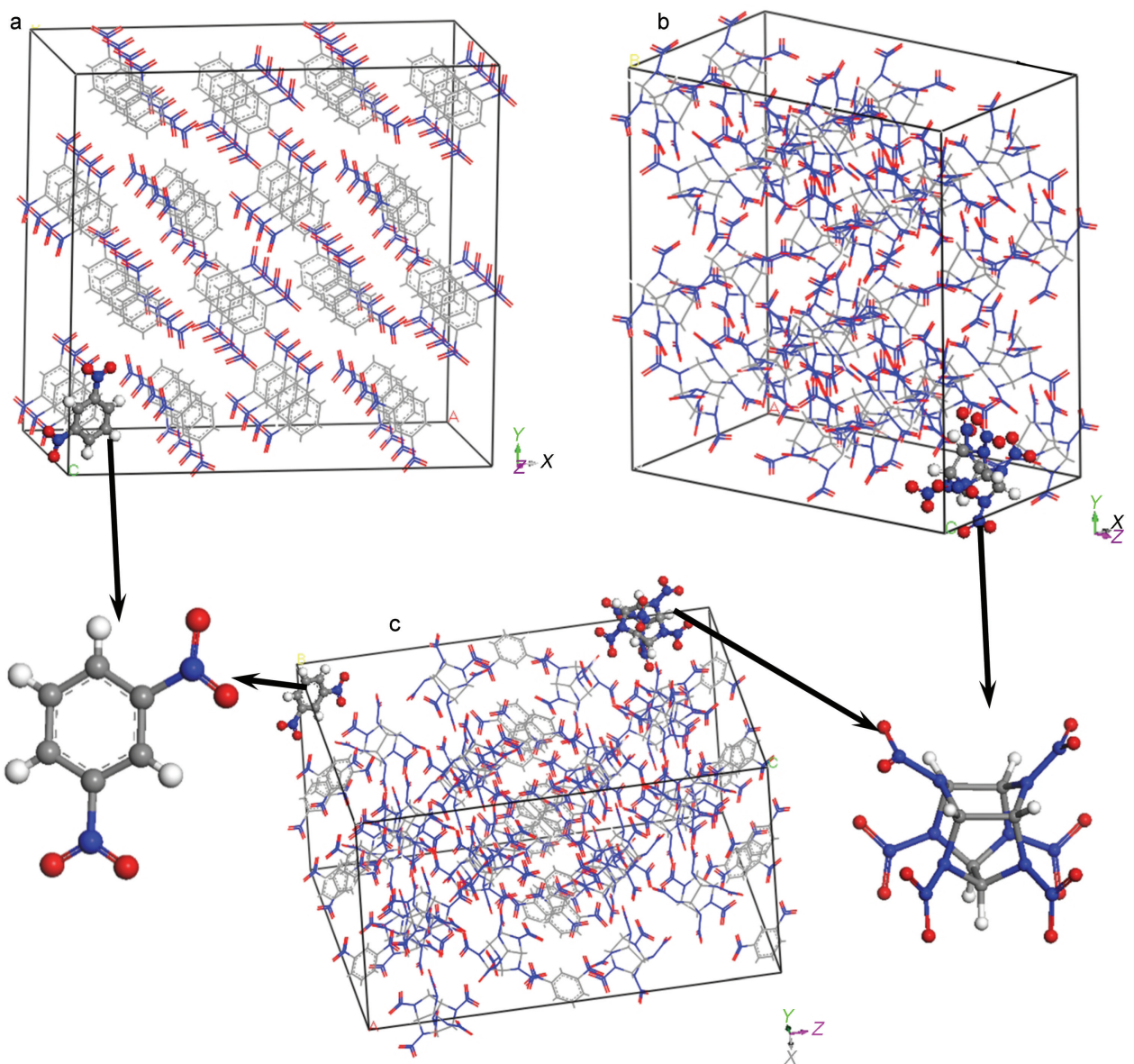

Fig.1 Crystal structures of DNB, CL20, and co-existent CL20/DNB

(a) pure crystal of DNB, (b) pure crystal of CL20, (c) co-crystal of CL20/DNB. The C, H, O, N are represented by grey, white, red, and blue balls, respectively. color online

sequently, dramatic exothermic reaction occurs, which results in gradual increase of the temperature and pressure until a final plateau of the system.

\subsection{Potential energy evolution}

Fig.4 shows the potential energy evolution of the three systems during and after the FLA process. During the FLA process, all three systems display a jump in potential energy. After the ablation process, the potential energy for both CL20 and CL20/DNB systems rapidly decays. However, the potential energy of the DNB system initially maintains and then starts to decline. Moreover, the potential energy of the CL20 system decays the fastest ( $0-8 \mathrm{ps})$ in three systems, and its decay rate gradually increases. This is due

Table 1 Crystal lattice parameters ${ }^{25}$ for CL20, DNB, and CL20/DNB co-crystal

\begin{tabular}{cccccc}
\hline \multirow{2}{*}{ Sample } & \multirow{2}{*}{ Method } & \multicolumn{4}{c}{ Parameters of crystal } \\
\cline { 3 - 6 } & & $\rho /\left(\mathrm{g} \cdot \mathrm{cm}^{-3}\right)$ & $a / \mathrm{nm}$ & $b / \mathrm{nm}$ & $c / \mathrm{nm}$ \\
\hline \multirow{2}{*}{ CL20 } & ReaxFF/lg & 1.887 & 0.8961 & 1.2718 & 1.3538 \\
& experiment & 2.086 & 0.8789 & 1.2474 & 1.3279 \\
CL20/DNB & ReaxFF/lg & 1.817 & 0.9578 & 1.3611 & 3.4000 \\
& experiment & 1.880 & 0.9470 & 1.3459 & 3.3620 \\
\multirow{2}{*}{ DNB } & ReaxFF/lg & 1.591 & 1.4018 & 1.3229 & 0.3784 \\
& experiment & 1.569 & 1.4084 & 1.3292 & 0.3802 \\
\hline
\end{tabular}

to the fact that the CL20 system is autocatalytic in its thermal decomposition $^{27}$. For the CL20 and CL20/DNB systems, the potential energy depicts a slow growth after the decay, which is consistent with the slow increase in temperature. Therefore, the potential energy increase is likely caused by the temperature rise that leads to the decompositions of $\mathrm{H}_{2} \mathrm{O}, \mathrm{N}_{2}$, and $\mathrm{CO}_{2} . \mathrm{H}_{2} \mathrm{O}$ has been previously reported to decompose at high temperatures ${ }^{28}$.

\subsection{Product analysis}

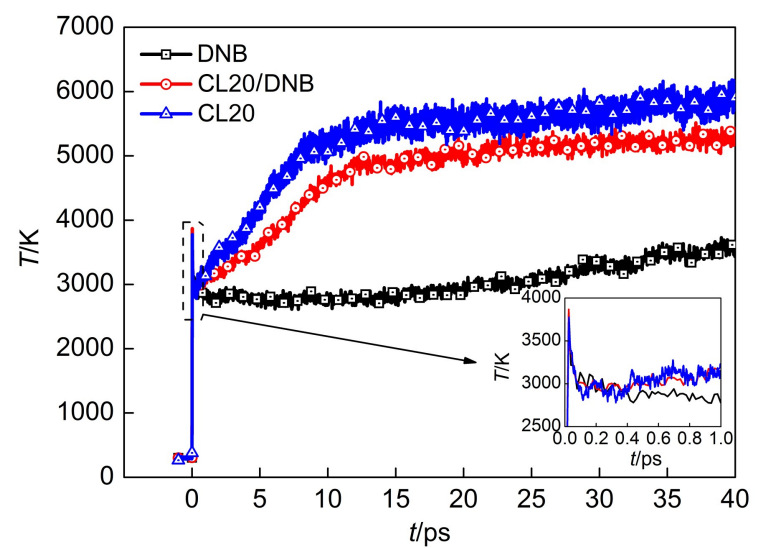

Fig.2 Time evolutions of temperature for the CL20, DNB, and CL20/DNB systems 


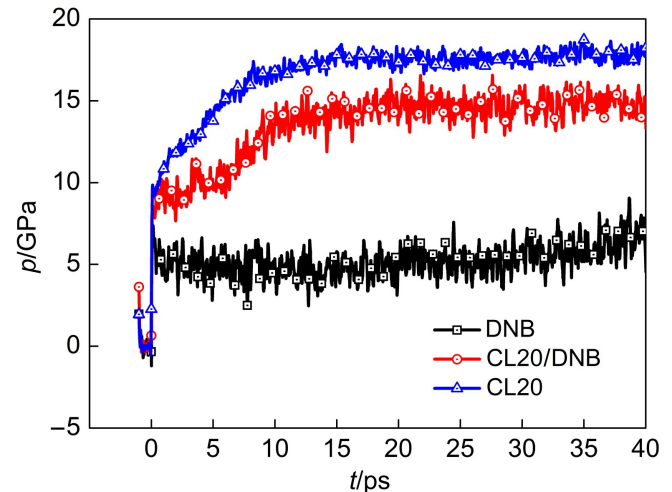

Fig.3 Time-dependent pressure evolutions of the CL20, DNB, and CL20/DNB system

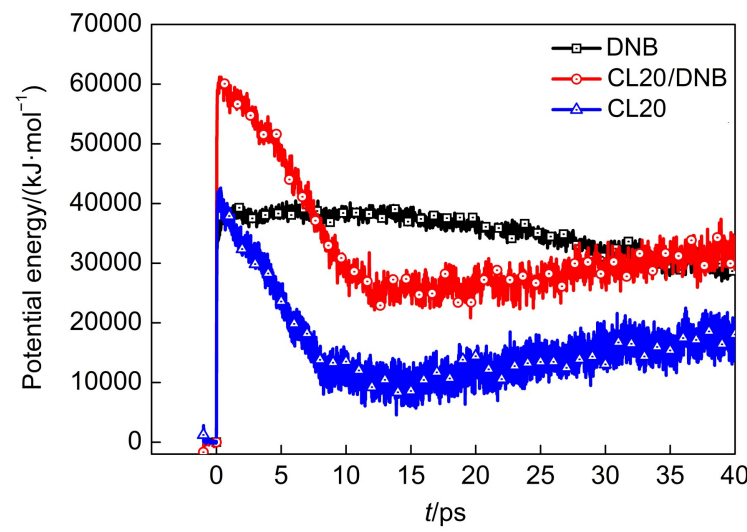

Fig.4 Time-dependent evolution of the normalized potential energy for the CL20, DNB, and CL20/DNB system The potential energy at $t=0 \mathrm{ps}$ is set to be zero.

Fig.5 shows main product distributions of the CL20, DNB, and CL20/DNB systems. For both CL20 and CL20/DNB systems, the CL20 molecule is consumed up in a very short period of time. The DNB consumption rate is, however, smaller in the DNB system than in the CL20/DNB system. The main products in the system are $\mathrm{NO}_{2}, \mathrm{NO}, \mathrm{N}_{2}, \mathrm{CO}_{2}, \mathrm{HNO}, \mathrm{HONO}$, and $\mathrm{HNO}_{3}$. In all three systems, $\mathrm{NO}_{2}$ first evolves, because $\mathrm{N}-\mathrm{NO}_{2}$ of CL20 molecule and $\mathrm{C}-\mathrm{NO}_{2}$ of DNB molecule are the weakest, and then becomes dominant as a main intermediate, which is consistent with the experimental observation that $\mathrm{NO}_{2}$ is first produced in the thermal decompositions of the CL20 and DNB molecules ${ }^{29,30}$. For both CL20 and CL20/DNB systems, $\mathrm{NO}_{2}$ follows a similar consumption pattern: it sharply increases at the very beginning of the reaction, reaches the maximum within about 2 ps, and then vigorously decreases due to its involvement in subsequent reaction, such as $\mathrm{NO}_{2} \rightarrow \mathrm{ONO} \rightarrow \mathrm{NO}+$ oxygen radical (which in contrast proceeds less rapidly for the CL20/DNB system). The simulation results are in excellent agreement with the fact that the thermal sensitivity of the CL20/DNB system is lower than the CL20 system $^{25}$. In the DNB system, the evolution of $\mathrm{NO}_{2}$ undergoes an up-down pattern, but the changing rate is significantly smaller than those for both CL20 and CL20/DNB systems, and hence the time for the CL20 system to achieve its maximum (in approxi-
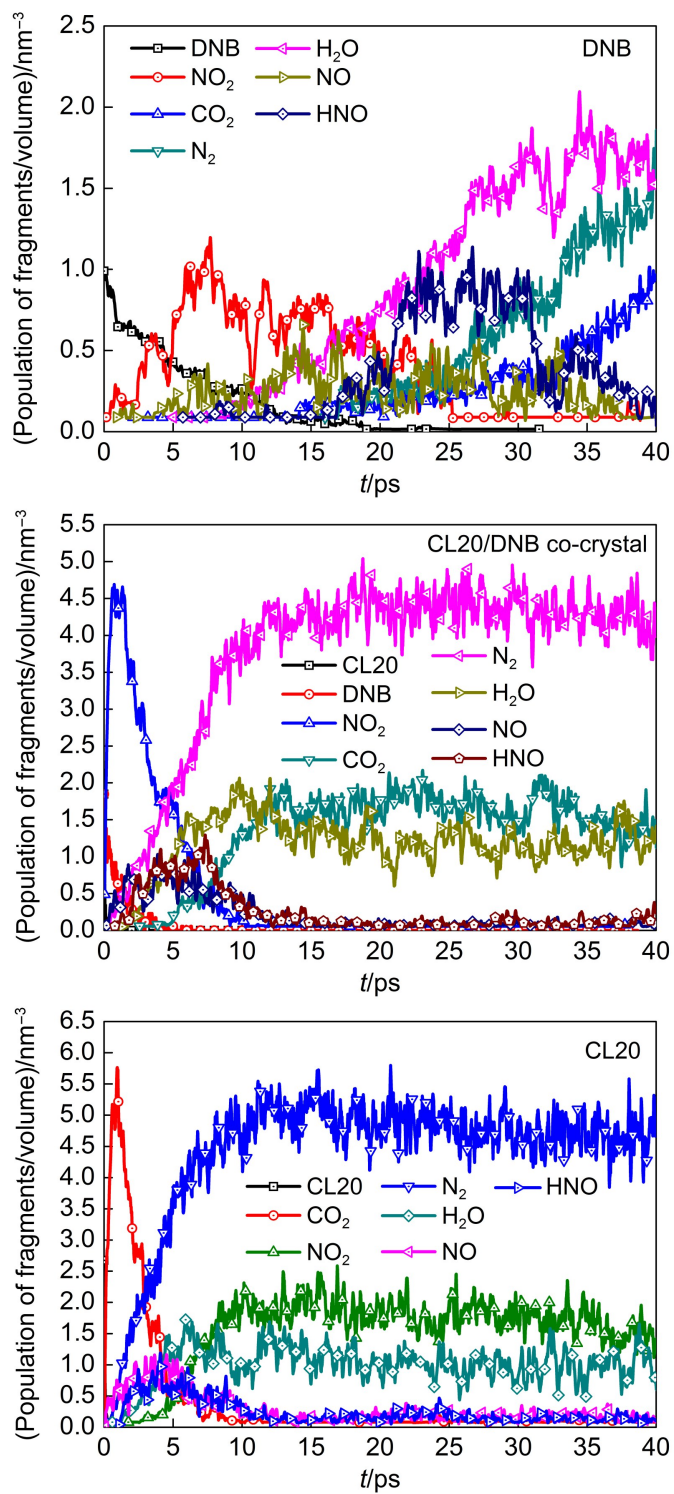

Fig.5 Product evolutions for the CL20, DNB, and CL20/DNB systems

mately $8 \mathrm{ps}$ ) is much longer. It is because bond dissociation energy (BDE) of $\mathrm{C}-\mathrm{NO}_{2}$ for DNB molecule (about $305 \mathrm{~kJ} \cdot \mathrm{mol}^{-1}$ ) is larger than that of $\mathrm{N}-\mathrm{NO}_{2}$ for CL20 (about $100 \mathrm{~kJ} \cdot \mathrm{mol}^{-1}$ ).

In all three systems, $\mathrm{N}_{2}, \mathrm{H}_{2} \mathrm{O}$, and $\mathrm{CO}_{2}$ are the most important final products, but their evolution patterns are quite different. In the DNB system, $\mathrm{CO}_{2}$ first appears at about $2 \mathrm{ps}$, and starts to gradually increase at $14 \mathrm{ps} ; \mathrm{H}_{2} \mathrm{O}$ comes into appearance at about 5 ps, gradually increases from $10 \mathrm{ps}$, reaches its maximum at $35 \mathrm{ps}$ and then remains stable; $\mathrm{N}_{2}$ occurs at about $16 \mathrm{ps}$ and then gradually increases. The sequence of the production rate is $r\left(\mathrm{H}_{2} \mathrm{O}\right)>r\left(\mathrm{~N}_{2}\right)>r\left(\mathrm{CO}_{2}\right)$. The production rate of $\mathrm{CO}_{2}$ is the smallest, because benzene is relatively stable, for BDE of $\mathrm{C}-\mathrm{C}$ of benzene in DNB molecule is about $627 \mathrm{~kJ} \cdot \mathrm{mol}^{-1}$, which is a lot larger than that of $\mathrm{C}-\mathrm{N}\left(305 \mathrm{~kJ} \cdot \mathrm{mol}^{-1}\right)$ and of $\mathrm{C}-\mathrm{H}(418 \mathrm{~kJ} \cdot$ $\left.\mathrm{mol}^{-1}\right)$. Compared with the results depicted in Fig.4, the potential energy for all three systems starts to decrease upon the increase of 
the $\mathrm{N}_{2}$ and $\mathrm{CO}_{2}$ products. For the CL20 and CL20/DNB systems, $\mathrm{N}_{2}, \mathrm{H}_{2} \mathrm{O}$, and $\mathrm{CO}_{2}$ follow a similar evolution pattern, augment up to a plateau before a slow decrease. During the product evolutions, the reaction rates of $\mathrm{N}_{2}, \mathrm{H}_{2} \mathrm{O}$, and $\mathrm{CO}_{2}$ in different systems change by $r(\mathrm{CL} 20)>r(\mathrm{CL} 20 / \mathrm{DNB})$; the reaction rates of the products change by $r\left(\mathrm{~N}_{2}\right)>r\left(\mathrm{H}_{2} \mathrm{O}\right)>r\left(\mathrm{CO}_{2}\right)$ in the same system.

The CL20 system decomposes faster than its CL20/DNB counterpart. Fig. 5 shows that all important intermediates follow a similar evolutionary pattern for both CL20 and CL20/DNB systems, and the production and consumption rates of the intermediates are higher in the CL20 system than in the CL20/DNB counterpart. The important intermediates are consumed up at 10 ps in the CL20 system and at about 15 ps in the CL20/DNB system. For instance, HNO gradually appears in $0-5$ ps and disappears in 5-10 ps in the CL20 system while the time slots for the corresponding appearance and disappearance of the $\mathrm{HNO}$ species in the CL20/DNB system are $0-8$ ps and $10-15$ ps, respectively.

\subsection{Initial reaction pathways for CL20 and CL20/DNB}

According to the product analyses, the initial reaction pathway for the CL20 crystal could be the follows.

$$
\begin{aligned}
& \text { Path I: } \\
& \mathrm{C}_{6} \mathrm{H}_{6} \mathrm{~N}_{12} \mathrm{O}_{12} \rightarrow \mathrm{NO}_{2}+\mathrm{C}_{6} \mathrm{H}_{6} \mathrm{~N}_{11} \mathrm{O}_{10}, \\
& \mathrm{C}_{6} \mathrm{H}_{6} \mathrm{~N}_{11} \mathrm{O}_{10} \rightarrow \mathrm{NO}_{2}+\mathrm{C}_{6} \mathrm{H}_{6} \mathrm{~N}_{10} \mathrm{O}_{8}, \\
& \mathrm{C}_{6} \mathrm{H}_{6} \mathrm{~N}_{10} \mathrm{O}_{8} \rightarrow \mathrm{NO}_{2}+\mathrm{C}_{6} \mathrm{H}_{6} \mathrm{~N}_{9} \mathrm{O}_{6} . \\
& \text { Path II: } \\
& \mathrm{C}_{6} \mathrm{H}_{6} \mathrm{~N}_{12} \mathrm{O}_{12} \rightarrow \mathrm{C}_{6} \mathrm{H}_{6} \mathrm{~N}_{10} \mathrm{O}_{10}+\mathrm{N}_{2} \mathrm{O}_{2}, \\
& \mathrm{C}_{6} \mathrm{H}_{6} \mathrm{~N}_{10} \mathrm{O}_{10} \rightarrow \mathrm{C}_{6} \mathrm{H}_{6} \mathrm{~N}_{9} \mathrm{O}_{8}+\mathrm{NO}_{2} . \\
& \text { Path III: } \\
& \mathrm{C}_{6} \mathrm{H}_{6} \mathrm{~N}_{12} \mathrm{O}_{12} \rightarrow \mathrm{NO}_{3}+\mathrm{C}_{6} \mathrm{H}_{6} \mathrm{~N}_{11} \mathrm{O}_{9} .
\end{aligned}
$$

In these initial reaction pathways, Path I turns out to be dominating according to the product distributions in Fig.5. The simulation results point out that in the CL20/DNB co-crystal system, the CL20 molecule first decomposes in a way similar to the initial reaction pathway in pure CL20 crystal. However, the consumed DNB molecule in the initial processes does not decompose, but correspondingly reacts with the CL20 molecule and its decomposition products to convert into $\mathrm{C}_{10} \mathrm{H}_{10} \mathrm{~N}_{14} \mathrm{O}_{16}, \mathrm{H}_{10} \mathrm{C}_{12} \mathrm{~N}_{11} \mathrm{O}_{10}$ and $\mathrm{H}_{10} \mathrm{C}_{12} \mathrm{~N}_{14} \mathrm{O}_{15}$ via the following reaction equations:

$\mathrm{C}_{6} \mathrm{H}_{4} \mathrm{~N}_{2} \mathrm{O}_{4}+\mathrm{NO}_{2} \rightarrow \mathrm{C}_{6} \mathrm{H}_{4} \mathrm{~N}_{3} \mathrm{O}_{6}$

$\mathrm{C}_{6} \mathrm{H}_{4} \mathrm{~N}_{3} \mathrm{O}_{6}+\mathrm{NO}_{2} \rightarrow \mathrm{C}_{6} \mathrm{H}_{4} \mathrm{~N}_{4} \mathrm{O}_{8}$

The involved DNB molecule in the reaction also turns into $\mathrm{C}_{6} \mathrm{H}_{4} \mathrm{~N}_{3} \mathrm{O}_{6}, \mathrm{C}_{6} \mathrm{H}_{4} \mathrm{~N}_{4} \mathrm{O}_{8}$, and $\mathrm{C}_{10} \mathrm{H}_{10} \mathrm{~N}_{14} \mathrm{O}_{16}$. These benzene-containing molecules are rather stable and can substantially reduce the effective collision probabilities between CL20 and its intermediates, and thus lower the CL20 thermal decomposition rate. This may well explain why the CL20/DNB co-crystal decomposes at a slower rate than the CL20 crystal.

\section{Conclusions}

In summary, the FLA of the DNB, CL20, and CL20/DNB systems have been computationally simulated by using the ReaxFF/lg reactive molecular dynamics. The physical and chemical response processes of the energetic materials in and after the FLA process were scrutinized. Both temperature and pressure in the CL20/DNB system generally jump in the FLA process, and gradually reach their maxima after having experienced a cooling process. In the process, the trigger reaction in the CL20 crystal and the CL20/DNB co-crystal stems from the $\mathrm{N}-\mathrm{NO}_{2}$ bond-breaking of the involved CL20 molecule. The decomposition rate in the CL20 system is greater than that in the CL20/DNB co-crystal counterpart because the co-existent DNB molecule in the cocrystal system and rather stable benzene-containing decomposition products can significantly reduce the effective collision probabilities between the CL20 molecule and its products. Our study actually provides atom-scale information on the initial reaction processes involved in the CL20, DNB, and CL20/DNB systems upon the FLA, which may help to theoretically understand for the femtosecond laser machining of energetic materials with the effective ReaxFF/lg simulation approach.

\section{References}

(1) Maxwell, I.; Chung, S.; Mazur, E. Medical Laser Appl. 2005, 20, 193. doi: 10.1016/j.mla.2005.07.005

(2) Zhao, L. H.; Wei, Z. Y.; Zhang, J. Physics 2002, 31, 729. [赵玲 慧, 魏志义, 张 杰. 物理, 2002, 31, 729.] doi: 10.3321/j.issn: 0379-4148.2002.11.008

(3) Chen, G. F. J. Phys. A: Math. Gen. 2001, 34, 757.

(4) He, F.; Cheng, Y. Chin. J. Lasers 2007, 34, 595. [何 飞, 程 亚. 中国激光, 2007, 34, 595.]

(5) Mishra, S.; Yadava, V. Opt. Laser Eng. 2015, 73, 89. doi: 10.1016/j.optlaseng.2015.03.017

(6) Wang, W. T.; Zhang, N.; Wang, M. W.; He, Y. H.; Yang, J. J.; Zhu, X. N. Acta Phys. Sin. 2013, 62, 170601. [王文亭, 张 楠, 王明伟, 何远航, 杨建军, 朱晓农. 物理学报, 2013, 62, 170601.] doi: 10.7498/aps.62.170601

(7) Zhang, N.; Zhao, Y. B.; Zhu, X. N. Opt. Express. 2004, 12, 3590. doi: 10.1364/OPEX.12.003590

(8) Wang, W. T.; Hu, B.; Wang, M. W. Acta Phys. Sin. 2013, 62, 060601. [王文亭, 胡 冰, 王明伟. 物理学报, 2013, 62, 060601.] doi: 10.7498/aps.62.060601

(9) Roos, E. V.; Benterou, J. J.; Lee, R. S.; Roeske, F.; Stuart, B. C. Femtosecond Laser Interaction with Energetic Materials. In Proceedings of SPIE. Phipps, C. R. Ed.; International Society for Optics and Photonics: Taos, NM, 2002; 415.

(10) Roeske, F.; Benterou, J.; Lee, R.; Roos, E. Propell. Explos. Pyrot. 2003, 28, 53. doi: 10.1002/prep.200390008

(11) Chen, H. M.; Lu, B.; Li, C. G.; Liu, H. T. Initiat. Pyrot. 2005, 5, 42. [陈明华, 卢 斌, 李成国, 刘海涛. 火工品, 2005, 5, 42.]

(12) Yang, J. J. Laser Opt. Prog. 2004, 41, 42. [杨建军. 激光与光电 子学进展, 2004, 41, 42.]

(13) Chen, M. H.; Gao, M.; Zhang, G. A.; Wang, H. J.; Wang, X. Electron-Optic Technol. Appl. 2006, 21, 4. [陈明华, 高 敏, 张 国安, 汪海军, 王 宪. 光电技术应用, 2006, 21, 4.]

(14) Chen, M. H.; Lu, B.; Li, D. Y.; Zhan, Z. B. Laser Infr. 2007, 37, 
214. [陈明华, 卢 斌, 李东阳, 战志波. 激光与红外, 2007, 37, 214.]

(15) Yang, Z.; He, Y. H. Acta Phys. -Chim. Sin. 2016, 32, 921. [杨 镇, 何远航. 物理化学学报, 2016, 32,921.] doi: 10.3866/PKU. WHXB201512251

(16) Chenoweth, K.; Cheung, S.; van Duin, A. C. T.; Goddard, W. A.; Kober, E. M. J. Am. Chem. Soc. 2005, 127,7192. doi: 10.1021/ ja050980t

(17) van Duin, A. C. T.; Zeiri, Y.; Dubnikova, F.; Kosloff, R.; Goddard, W. A. J. Am. Chem. Soc. 2005, 127, 11053. doi: $10.1021 / \mathrm{ja} 052067 \mathrm{y}$

(18) Cheng, T.; Jaramillo-Botero, A.; Goddard, W. A.; Sun, H. J. Am Chem. Soc. 2014, 136, 9434. doi: 10.1021/ja5037258

(19) Furman, D.; Kosloff, R.; Dubnikova, F.; Zybin, S. V.; Goddard, W. A.; Rom, N.; Hirshberg, B.; Zeiri, Y. J. Am. Chem. Soc. 2014, 136, 4192.doi: 10.1021/ja410020f

(20) Ye, C. C.; An, Q.; Goddard, W. A.; Cheng, T.; Liu, W. G.; Zybin, S. V.; Ju, X. H. J. Mater. Chem. A 2015, 3, 1972. doi: 10.1039/ c4ta05676k

(21) Guo, D. Z.; An, Q.; Zybin, S. V.; Goddard, W. A.; Huang, F. L; Tang, B. J. Mater. Chem. A 2005, 3, 5409. doi: 10.1039/ C4TA06858K
(22) Zhang, L. Z.; van Duin, A. C. T.; Zybin, S. V.; Dasgupta, S.; Goddard, W. A. J. Phys. Chem. A 2009, 113, 10619. doi: $10.1021 /$ jp900194d

(23) Ge, N. N.; Wei, Y. K.; Song, Z. F.; Chen, X. R.; Ji, G. F.; Zhao, F.; Wei, D. Q. J. Phys. Chem. B 2014, 118, 8691. doi: 10.1021/ jp502432g |

(24) http://lammps.sandia.gov/ (accessed March 5, 2016).

(25) Wang, Y. P.; Yang, Z. W.; Li, H. Z.; Zhang, Q.; Wang, J. H.; Liu, Y. C. Propellants, Explos., Pyrotech. 2014, 39, 590. doi: 10.1002/prep.201300146

(26) Wojcik, G.; Mossakowska, I.; Holband, J.; Bartkowiak, W. Acta Crystallogr., Sect. B: Struct. Sci. 2002, 58, 998. doi: 10.1107/ S0108768102015033

(27) Geetha, M.; Nair, U. R.; Sarwade, D. B.; Gore, G. M.; Asthana, S. N.; Singh, H. J. Therm. Anal. Calorim. 2003, 73, 913.

(28) Wu, C. J.; Fried, L. E.; Yang, L. H.; Goldman, N.; Bastea, S. Nat. Chem. 2009, 1, 57. doi: 10.1038/NCHEM.130

(29) Nair, U. R.; Sivabalan, R.; Gore, G. M.; Geetha, M.; Asthana, S. N.; Singh, H. Combust., Explo. Shock Waves 2005, 41, 121.

(30) Turcotte, R.; Vachon, M.; Kwok, Q. S. M.; Wang, R. P.; Jone, D. E. G. Themochim. Acta 2005, 433, 105. doi: 10.1016/j. tca.2005.02.021 